\title{
Anterior capsulotomy improves persistent developmental stuttering with a psychiatric disorder: a case report and literature review
}

This article was published in the following Dove Press journal:

Neuropsychiatric Disease and Treatment

I April 2014

Number of times this article has been viewed

\author{
Shizhen Zhang* \\ Peng Li* \\ Zhujun Zhang \\ Wei Wang
}

Department of Neurosurgery, West China Hospital, Sichuan University, Chengdu, Sichuan Province, People's Republic of China

*These authors contributed equally to this work
Correspondence: Wei Wang Department of Neurosurgery, West China Hospital, Sichuan University, 37 Guoxue Alley, Chengdu 61004I, Sichuan Province, People's Republic of China Emailwcnsww@163.com
Abstract: Stuttering is characterized by disrupted fluency of verbal expression, and occurs mostly in children. Persistent developmental stuttering (PDS) may occur in adults. Reports of the surgical management of PDS are limited. Here we present the case of a 28 -year-old man who had had PDS since the age of 7 years, was diagnosed with depression and anxiety disorder at the age of 24 years, and had physical concomitants. He underwent a bilateral anterior capsulotomy 4 years after the diagnosis. Over one year of follow-up, his physical concomitants resolved, and significant improvements in his psychiatric disorders and PDS were observed. To the best of our knowledge, this is the first report of simultaneous improvement in a patient's PDS and psychiatric disorder after a bilateral anterior capsulotomy.

Keywords: persistent developmental stuttering, psychiatric disorders, anterior capsulotomy

\section{Introduction}

Stuttering is a disorder defined by frequent prolongations, repetitions, or blocks of spoken sounds and/or syllables, as well as anxiety and cognitive avoidance. Coexisting symptoms may include facial grimacing and tremors of the muscles involved in speech. ${ }^{1}$ Stuttering affects approximately $5 \%$ of children and $1 \%$ of the adult population. ${ }^{1}$ Most stuttering undergoes spontaneous recovery. ${ }^{1}$ Speech and language therapy is the most common treatment for stuttering. ${ }^{2}$

Persistent developmental stuttering (PDS) is a form of stuttering that occurs in early childhood and does not resolve spontaneously or respond to speech therapy. ${ }^{3}$ Many PDS patients have an increased risk of psychiatric and behavioral problems. ${ }^{4}$ Although successful surgical management of patients with refractory psychiatric disorders has been reported, ${ }^{5,6}$ the evidence for surgical treatment of PDS and associated psychiatric disorders is limited. ${ }^{7}$

\section{Case report}

A 28-year-old male first presented with stuttering at the age of 7 years. No management was carried out at that time because his symptoms were mild. By the age of 20 years, he was being ridiculed and humiliated by his college classmates. He became more introverted and did not want to communicate with others. Since then, his stuttering had worsened. He experienced multiple blocks in expressing words, including sound and syllable repetitions, circumlocutions, and monosyllabic repetitions, that made it difficult to conduct the interview.

In addition to deterioration of his PDS, he developed depression and anxiety and was afraid to communicate with others. He also had physical concomitants of involuntary 
jerking of his head and upper extremities and muscle spasm of his neck and lower jaw while stuttering. He was diagnosed with depression and anxiety disorder by the psychiatrists at the age of 24 years. He was managed medically with multiple antipsychotics in conjunction with cognitive behavioral therapy. Significant improvement in his psychiatric disorder but not his PDS was achieved at that time.

One year earlier, because of his local culture, he had refused to take any medicine, which led to a relapse of his psychiatric symptoms. Subsequent antipsychotics and cognitive behavioral therapy were of limited help in alleviating his psychiatric symptoms. We carefully addressed his treatment options, which included further medical treatment, deep brain stimulation, or capsulotomy. Both the patient and his family opted for capsulotomy for financial reasons and in the hope of being able to avoid using antipsychotics. The surgery was approved by the ethics committee at our hospital.

Preoperative magnetic resonance imaging was done to rule out an intracranial tumor, hemorrhage, infarction, and infection. No family history of a speech disorder was reported. The preoperative neuropsychological evaluations were carried out using the 24-item Hamilton Depression Rating Scale, ${ }^{8}$ the Hamilton Anxiety Rating Scale, ${ }^{9}$ the Mini-Mental State Examination, ${ }^{10}$ the similarities and block design subtests of the Wechsler Adult Intelligence scale, ${ }^{11}$ the logical memory and visual reproduction subtests of the Wechsler Memory Scale, ${ }^{12}$ and the Wisconsin Card Sorting Test-Simplified (WCST-S). ${ }^{13}$ Both the logical memory and visual reproduction tests were carried out immediately and after a 30-minute delay. The WCST-S included 48 cards, and his performance was assessed by the number of correct answers, number of errors, number of perseverative errors, number of nonperseverative errors, and number of categories completed. Neuropsychological and PDS evaluations were done before surgery and at 6-month follow-up by the same psychiatrist and speech therapist, who were both aware that the patient had undergone neurosurgery.

\section{Surgery}

To better identify the magnetic resonance images without fixation of the head frame were obtained the day before surgery. A 3 T Trio Unite magnetic resonance imaging system (Siemens AG, Muenchen, Germany) was used with T1-weighted and T2-weighted spin-echo sequences in the axial and coronal planes. The slice thickness was $2 \mathrm{~mm}$ with an interval gap of $0.02 \mathrm{~mm}$. The preplanning procedure was completed using the Surgi-plan workstation (version 2.1; Elekta Instruments AB, Stockholm, Sweden). On the day of surgery, a Leksell model $\mathrm{G}$ head frame (Elekta Instruments $\mathrm{AB}$ ) was positioned on the skull parallel to the anterior commissure-posterior commissure line under local anesthesia. A repeat magnetic resonance scan with the same parameters as the preplanning scanning was performed using a 1.5 T Sonata Unite magnetic resonance imaging system (Siemens AG). With the help of the Surgi-plan workstation, the prescanned images were then coregistered with the images using location markers. The coordinates of the target and the angles of electrode penetration were calculated. The lesion targets were located $14 \mathrm{~mm}$ anterior and $18 \mathrm{~mm}$ lateral to the anterior commissure and $5 \mathrm{~mm}$ below the anterior commissure-posterior commissure plane. Under the guidance of the Leksell multifunctional stereotactic operation system (Elekta Instruments AB), the lesion electrode was then inserted into the lesion target according to the calculated coordinates. A test stimulation generated by the Elekta neurostimulator at both high frequency $(130 \mathrm{~Hz})$ and low frequency $(5 \mathrm{~Hz})$ was then carried out to verify the target of the electrode. Next, multiple lesions were produced using the Elekta neurostimulator at $75^{\circ} \mathrm{C}$ for 70 seconds each. The length of the lesions on both sides was $14 \mathrm{~mm}$ (Figures 1 and 2).

\section{Post-surgical outcome}

The patient's physical concomitants disappeared on the second day after surgery. Slow reaction, lack of concentration,

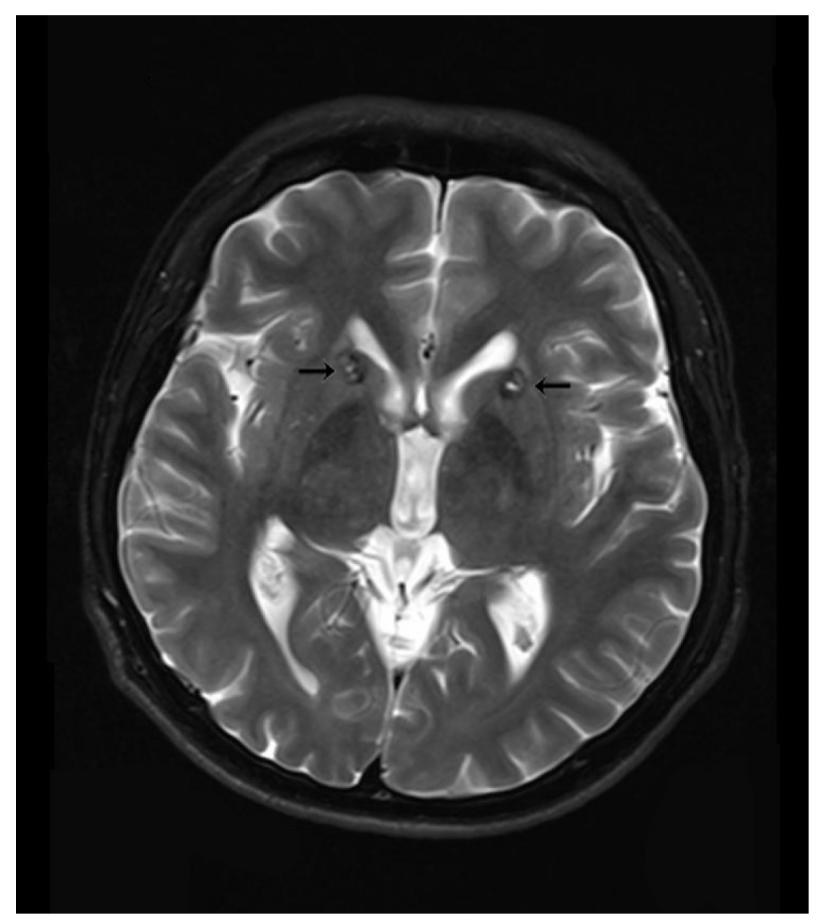

Figure I Lesions in the anterior limb of the internal capsule 3 months after surgery.

Note: Arrows indicate lesions. 


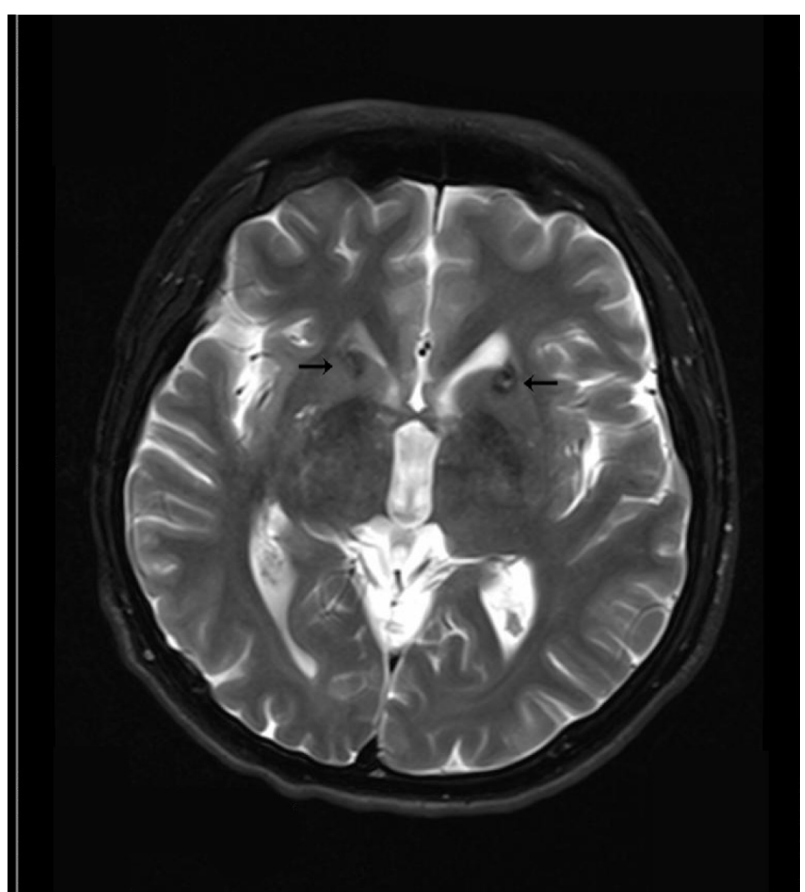

Figure 2 Lesions in the anterior limb of the internal capsule 6 months after surgery.

Note: Arrows indicate lesions.

and mild somnolence were observed during the first week, but most of these symptoms disappeared 10 days after surgery.

One month after surgery, the patient reported improvement in his symptoms of depression, anxiety, and PDS, except for some naïve behaviors (sucking and biting his fingers), mild memory loss, and laziness. Three months after surgery, the patient reported being interested in daily life and feeling more confident. Six months after surgery, the patient reported that his psychiatric symptoms were significantly improved. Although the symptoms of his PDS occurred occasionally, these were mild and could be controlled by ego psychology. Complete remission of the naïve behaviors, mild memory loss, and laziness were documented 1 month after surgery. One year after surgery, the patient returned to work, reporting improved mood and better social and work relationships. Although complete remission of his PDS was not achieved, he could communicate with others more fluently.

\section{Stuttering}

Six months after surgery, the patient's symptoms improved from very severe speech impairments on the Stuttering Severity Instrument $3^{14}$ and $8 / 9$ for speech naturalness ${ }^{15}$ to mild speech impairments on the Stuttering Severity Instrument 3 and 3/9 for speech naturalness. Both the severity of stuttering and naturalness of speech improved significantly 6 months after surgery.

\section{Neuropsychological status}

Neuropsychological evaluations (Table 1) were carried out before surgery, 1 month after surgery, 3 months after surgery, and 6 months after surgery. His scores on the Hamilton Depression Rating Scale and Hamilton Anxiety Rating Scale decreased markedly 6 months after surgery, which is in accordance with the significant improvement in his psychiatric symptoms at 6-month follow-up. Neuropsychological evaluation tests were used to assess and detect whether there were neurocognitive impairments after surgery.

Cognitive impairment is common in young adults with major depression and anxiety disorder. ${ }^{16}$ The raw data from the block design, logical memory, and WCST-S indicate that the patient's impairments of visuospatial function, verbal memory, concentration, and executive function before surgery were significantly improved 6 months after surgery. ${ }^{16}$ The raw data for the WCST-S at 1 month after surgery, which were lower than the data before surgery but increased at 6-month follow-up, showed that his executive functioning worsened transiently following surgery and improved thereafter. This may be why the patient had naïve behaviors, mild memory loss, and laziness at the 1 month follow-up that completely disappeared 6 months after surgery. ${ }^{13}$

Table I Neuropsychological evaluation tests at 6-month follow-up

\begin{tabular}{lllll}
\hline & BF & OMAS & TMAS & SMAS \\
\hline HAM-D (24-item) & 27 & 6 & 7 & 5 \\
HAM-A & 22 & 4 & 10 & 6 \\
MMSE & 29 & 28 & 29 & 30 \\
SIMILARITIES & 23 & 20 & 22 & 21 \\
BD & 31 & 37 & 41 & 38 \\
ILM & 3.5 & 8 & 8.5 & 8 \\
DLM & 1.5 & 7 & 9.5 & 8.5 \\
IVR & 14 & 14 & 14 & 14 \\
DVR & 14 & 14 & 14 & 14 \\
WCST-S & & & & 80 \\
$\quad$ Correct & 36 & 34 & 38 & 40 \\
Error & 12 & 14 & 10 & 0 \\
PE & 6 & 12 & 4 & 3 \\
NPE & 6 & 2 & 6 & 3 \\
$\quad$ Categories & 3 & 3 & & 8 \\
\hline
\end{tabular}

Abbreviations: BF, before surgery; HAM-D, 24-item Hamilton Depression Rating Scale; HAM-A, Hamilton Anxiety Rating Scale; BD, block design; MMSE, Mini-Mental State Examination; ILM, logical memory subtest of the Wechsler Memory Scale carried out immediately; IVR, visual reproduction subtest of the Wechsler Memory Scale carried out immediately; DLM, logical memory subtest of the Wechsler Memory Scale carried out after a 30-minute delay; DVR, visual reproduction subtest of the Wechsler Memory Scale carried out after a 30-minute delay; NPE, nonperseverative errors; WCST-S, Wisconsin Card Sorting Test-Simplified; PE, perseverative errors; OMAS, I month after surgery; TMAS, 3 months after surgery; SMAS, 6 months after surgery. 


\section{Discussion}

The tics associated with Tourette's syndrome are defined as involuntary, sudden, rapid, recurrent, nonrhythmic movements (motor tics) or vocalizations (vocal or phonic tics). The onset of Tourette's syndrome is before the age of 18 years. Patients with Tourette's syndrome can voluntarily suppress tics for short periods at the expense of mounting inner tension and a subsequent rebound in tic severity. ${ }^{17}$ Our patient had involuntary movements when he was 20 years old, which occurred only when he stuttered. He was not able to suppress these movements, as in Tourette's syndrome. We consider these involuntary movements to be physical concomitants of his PDS.

The ventral prefrontal cortex is associated with depression, obsessive-compulsive disorder, and several psychiatric disorders. ${ }^{18}$ The ventral prefrontal cortex (vPFC) projections to the subcortical regions travel primarily in the internal capsule and external capsule. Subcortical fibers pass through the external capsule to the ventral anterior limb of the internal capsule. ${ }^{18}$ Thus, an anterior capsulotomy may affect the vPFC through the projectional fibers from the vPFC and result in significantly improved psychiatric symptoms. The axons from the vPFC reach cortical targets primarily via the uncinate fasciculus, extreme capsule, and superior longitudinal fasciculus. ${ }^{18}$ The frontal operculum supporting local phrase structure building was connected via the uncinate fasciculus to the anterior superior temporal gyrus which has been shown to be involved in phrase structure building. ${ }^{19}$ The extreme capsule is involved in the human language system. ${ }^{20}$ The superior longitudinal fasciculus is situated in the white matter of the parietal and frontal opercula and extends to the ventral premotor and prefrontal regions. ${ }^{21}$ All these studies show that there are association fibers between the frontal operculum and the vPFC. The left pars opercularis is where the intrinsic functional architecture of speech-language processes are altered in PDS patients. ${ }^{22}$ Therefore, an anterior capsulotomy may affect the left pars opercularis through the vPFC and the association fibers between the vPFC and the pars opercularis, which are involved in the language system. The corticostriatothalamocortical (CSTC) pathways project from specific territories in the frontal cortex to corresponding targets within the striatum, then via pathways through the basal ganglia to the thalamus and, finally, with recurrent projections back to the original frontal territory where each loop started; this dysfunction and disorder of the chemistry circuit of the CSTC is a popular basis of neuropsychiatric diseases. ${ }^{23}$ Dorsal/ventral organization of thalamic/brainstem fibers through the internal capsule results in a complex mingling of thalamic and brainstem axons from various vPFC areas. ${ }^{18}$ Thus, there are association fibers between the vPFC and the CSTC.

Stutterers are likely to exhibit a hypometabolism of the striatum and increased dopamine activity. ${ }^{1,24}$ Overactivity in the area of the basal ganglia in PDS has been reported in several studies, suggesting that the dopaminergic system plays an important role in the development of stuttering. ${ }^{25,26}$ Most antipsychotics (Tables 2 and 3) are dopamine receptor antagonists and induce changes in the dopaminergic system and activity of the basal ganglia in the CSTC, and this is followed by improvement in psychiatric symptoms and PDS. ${ }^{1}$

Although improvements in PDS were an unexpected outcome in our patient, this report suggests a close relationship between PDS and psychiatric disorders.

Table 2 Case reports on the treatment of PDS in adults

\begin{tabular}{|c|c|c|c|c|}
\hline Reference & $\begin{array}{l}\text { Age } \\
\text { (years) }\end{array}$ & Sex & $\begin{array}{l}\text { Treatment and } \\
\text { dose ( } \mathrm{mg} / \text { day) }\end{array}$ & Summary of results \\
\hline \multirow[t]{2}{*}{ Dias et $\mathrm{al}^{3}$} & 24 & Female & Fluoxetine 20 and & From severe to moderate speech \\
\hline & & & Speech therapy & impairment (IS) \\
\hline Kumar et $\mathrm{al}^{27}$ & 22 & Male & Fluoxetine $10-20$ & "Complete disappearance" of stuttering \\
\hline Mozos-Ansorena et al ${ }^{28}$ & 33 & Male & Olanzapine 5 & "Significant improvement" in fluency \\
\hline \multirow[t]{3}{*}{ Maguire et $\mathrm{a}^{29}$} & 19 & Male & Asenapine 10 & $\begin{array}{l}75 \% \text { improvement in fluency (CGI-I) and } \\
\text { common side effect of sedation }\end{array}$ \\
\hline & 20 & Male & Asenapine 5 & $60 \%$ improvement in fluency (CGI-I) \\
\hline & 45 & Male & Asenapine 5 & $60 \%$ improvement in speech (CGI-I) \\
\hline Ranjan et $\mathrm{al}^{30}$ & 42 & Male & Risperidone $\mathrm{I}-2$ & PDS “disappeared completely" \\
\hline Tavano et $\mathrm{al}^{31}$ & 24 & Male & Risperidone 0.5 & "Significant improvement" in stuttering \\
\hline Tran et $\mathrm{al}^{32}$ & 38 & Male & Aripiprazole 5-15 & $58 \%$ reduction in total SSI-3 score \\
\hline Balamurali et $\mathrm{al}^{7}$ & 69 & Female & Craniotomy & "Improved dramatically" \\
\hline
\end{tabular}

Abbreviations: IS, lowa Scale; CGI-I, Clinical Global Impression of Improvement; PDS, persistent developmental stuttering; SSI-3, Stuttering Severity Instrument 3. 
Table 3 Controlled studies on the treatment of PDS in adults

\begin{tabular}{llllll}
\hline Reference & $\begin{array}{l}\text { Patients } \\
\text { (n) }\end{array}$ & $\begin{array}{l}\text { Age } \\
\text { (years) }\end{array}$ & $\begin{array}{l}\text { Treatment and } \\
\text { dose (mg/day) }\end{array}$ & $\begin{array}{l}\text { Follow-up } \\
\text { duration }\end{array}$ & Summary of result \\
\hline Maguire et al ${ }^{2}$ & 132 & $18-65$ & Pagoclone 0.3-0.6 & One year & $\begin{array}{l}40 \% \text { reduction in percentage of syllables } \\
\text { stuttered (SSI-3, CGI-I), headache was a } \\
\text { common adverse event } \\
\text { Risperidone was superior to a placebo in } \\
\text { the percent of syllables stuttered, time } \\
\text { spent stuttering, overall stuttering severity, } \\
\text { and treatment efficacy; it was well tolerated } \\
\text { CBT significantly and sustainably improved } \\
\text { Psychological functioning but did not }\end{array}$ \\
Menzies et al ${ }^{34}$ & 16 & $20-74$ & Risperidone 0.5-2 & 6 weeks & One year \\
\hline improve fluency
\end{tabular}

Abbreviations: PDS, persistent developmental stuttering; SSI-3, Stuttering Severity Instrument 3; CGI-I, Clinical Global Impression of Improvement; CBT, cognitive behavioral therapy.

\section{Disclosure}

The authors report no conflicts of interest in this work.

\section{References}

1. Maguire GA, Yeh CY, Ito BS. Overview of the diagnosis and treatment of stuttering. $J$ Exp Clin Med. 2012;4(2):92-97.

2. Maguire G, Franklin D, Vatakis NG, et al. Exploratory randomized clinical study of pagoclone in persistent developmental stuttering: the examining pagoclone for persistent developmental stuttering study. J Clin Psychopharmacol. 2010;30(1):48-56.

3. Dias FM, Pereira PM, Doyle FC, Teixeira AL. Psychiatric disorders in a patient with persistent developmental stuttering. Clin Neuropharmacol. 2011;34(5):199-200.

4. Iverach L, Jones M, O'Brian S, et al. The relationship between mental health disorders and treatment outcomes among adults who stutter. J Fluency Disord. 2009;34(1):29-43.

5. Ruck C, Karlsson A, Steele JD, et al. Capsulotomy for obsessivecompulsive disorder: long-term follow-up of 25 patients. Arch Gen Psychiatry. 2008;65(8):914-921.

6. Anderson RJ, Frye MA, Abulseoud OA, et al. Deep brain stimulation for treatment-resistant depression: efficacy, safety and mechanisms of action. Neurosci Behav Rev. 2012;36(8):1920-1933.

7. Balamurali G, Bukhari S, Carter J, Sofat A. Improvement of persistent developmental stuttering after surgical excision of a left perisylvianmeningioma. Br J Neurosurg. 2010;24(4):485-487.

8. Hamilton M. A rating scale for depression. J Neurol Neurosurg Psychiatry. 1960;23(1):56-62.

9. Hamilton M. The assessment of anxiety states by rating. $\mathrm{Br} J \mathrm{Med}$ Psychol. 1959;32(1):50-55.

10. Tombaugh TN, McIntyre NJ. The Mini-Mental State Examination: a comprehensive review. J Am Geriatr Soc. 1992;40(9):922-935.

11. Wechsler D. Manual for the Wechsler Adult Intelligence Scale. New York, NY, USA: Psychological Corporation; 1955.

12. Wechsler D. Wechsler Memory Scale. New York, NY, USA: Psychological Corporation; 1945.

13. Li B, Sun JH, Li T, Yang, YC. Neuropsychological study of patients with obsessive-compulsive disorder and their parents in China: searching for potential endophenotypes. Neurosci Bull. 2012;28(5):475-482.

14. Riley GD. A stuttering severity instrument for children and adults. J Speech Hear Disord. 1972;37(3):314-322.

15. Martin RR, Haroldson SK, Triden KA. Stuttering and speech naturalness. J Speech Hear Disord. 1984;49(1):53-58.

16. CastanedaAE, Tuulio-HenrikssonA, Marttunen M, Suvisaari J, Lönnqvist J. A review on cognitive impairments in depressive and anxiety disorders with a focus on young adults. JAffect Disord. 2008;106(1):1-27.
17. Cavanna AE, Seri S. Tourette's syndrome. BMJ. 2013;347:f4964.

18. Lehman JF, Greenberg BD, McIntyre CC, Rasmussen SA, Haber SN. Rules ventral prefrontal cortical axons use to reach their targets: implications for diffusion tensor imaging tractography and deep brain stimulation for psychiatric illness. J Neurosci. 2011;31(28):10392-10402.

19. Friederici AD. Pathways to language: fiber tracts in the human brain. Trends Cogn Sci. 2009;13(4):175-181.

20. Rolheiser T, Stamatakis EA, Tyler LK. Dynamic processing in the human language system: synergy between the arcuate fascicle and extreme capsule. J Neurosci. 2011;31(47):16949-16957.

21. Makris N, Kennedy DN, McInerney S, et al. Segmentation of subcomponents within the superior longitudinal fascicle in humans: a quantitative, in vivo, DT-MRI study. Cereb Cortex. 2005;15(6):854-869.

22. Lu C, Chen C, Peng D, et al. Neural anomaly and reorganization in speakers who stutter: a short-term intervention study. Neurology. 2012;79(7):625-632.

23. Milad MR, Rauch SL. Obsessive-compulsive disorder: beyond segregated cortico-striatal pathways. Trends Cogn Sci. 2012;16(1):43-51.

24. Wu JC, Maguire G, Riley G, et al. Increased dopamine activity associated with stuttering. Neuroreport. 1997;8(3):767-770.

25. Giraud AL, Neumann K, Bachoud-Levi AC, et al. Severity of dysfluency correlates with basal ganglia activity in persistent developmental stuttering. Brain Lang. 2008;104(2):190-199.

26. Alm PA. Stuttering and the basal ganglia circuits: a critical review of possible relations. J Commun Disord. 2004;37(4):325-369.

27. Kumar A, Balan S. Fluoxetine for persistent developmental stuttering. Clin Neuropharmacol. 2007;30(1):58-59.

28. Mozos-Ansorena A, Pérez-García M, Portela-Traba B, Tabernero-Lado A, Pérez-Pérez J. Stuttering treated with olanzapine: a case report. Actas Esp Psiquiatr. 2012;40(4):231-233.

29. Maguire GA, Franklin DL, Kirsten J. Asenapine for the treatment of stuttering: an analysis of three cases. Am J Psychiatry. 2011;168(6): $651-652$.

30. Ranjan S, Sawhney V, Chandra PS. Persistent developmental stuttering: treatment with risperidone. Aust N Z J Psychiatry. 2006;40(2):193.

31. Tavano A, Busan P, Borelli M, Pelamatti G. Risperidone reduces tic-like motor behaviors and linguistic dysfluencies in severe persistent developmental stuttering. J Clin Psychopharmacol. 2011;31(1):131-134.

32. Tran NL, Maguire GA, Franklin DL, Riley GD. Case report of aripiprazole for persistent developmental stuttering. J Clin Psychopharmacol. 2008;28(4):470-472.

33. Maguire GA, Riley GD, Franklin DL, Gottschalk LA. Risperidone for the treatment of stuttering. J Clin Psychopharmacol. 2000;20(4):479-482.

34. Menzies RG, O’Brian S, Onslow M, Packman A, St Clare T, Block S. An experimental clinical trial of a cognitive-behavior therapy package for chronic stuttering. J Speech Lang Hear Res. 2008;51(6):1451-1464. 


\section{Publish your work in this journal}

Neuropsychiatric Disease and Treatment is an international, peerreviewed journal of clinical therapeutics and pharmacology focusing on concise rapid reporting of clinical or pre-clinical studies on a range of neuropsychiatric and neurological disorders. This journal is indexed on PubMed Central, the 'PsycINFO' database and CAS.

The manuscript management system is completely online and includes a very quick and fair peer-review system, which is all easy to use. Visit http://www.dovepress.com/testimonials.php to read real quotes from published authors.

Submit your manuscript here: http://www.dovepress.com/neuropsychiatric-disease-and-treatment-journal 